\title{
Assessment of complications depending on the sliding screw position - finite element method analysis
}

\author{
Hrubina $\mathrm{M}^{1,2}$, Horak $\mathrm{Z}^{3,5}$, Skotak $\mathrm{M}^{1}$, Letocha $\mathrm{J}^{1}$, Baca $\mathrm{V}^{5}$, Dzupa $\mathrm{V}^{4}$ \\ Department of Orthopaedics, Hospital Pelhrimov, Slovanskeho bratrstvi 710, Pelhrimov, 393 01, Czech Republic. \\ mhrubina@gmail.com
}

\begin{abstract}
Objectives: The study was aimed at the assessment of specific complications depending on the sliding hip screw position.

Background: The finite element method in the biomechanical analysis of this implant may be used to predict the mechanical failure due to the screw position.

Methods: 380 sliding screw osteosyntheses for stable pertrochanteric fractures of 365 patients were included in the study. We divided and analysed the osteosyntheses with five various screw positions and focused on the specific complications development. For the construction of the finite element model of the femur, the program ABAQUS 6.9 was used. Analyses were performed with evaluation of the bone response to the different screw locations (strain and stress) with maximum low-cycle high stress loading.

Results: The specific complication rate was $10 \%$, with the re-operation rate of $4.2 \%$. If placing the screw in the middle third of the neck it reduced significantly strain patterns of the plate and screw. A screw position in the superior third of the neck significantly increased the strain of the plate and screw by more than $63 \%$.

Conclusions: The conformity in the clinical and biomechanical analyses was observed. The finite element model can be considered as valid in predicting sliding screw failures (Tab. 4, Fig. 8, Ref. 30). Text in PDF www.elis.sk. Key words: sliding hip screw, finite element method.
\end{abstract}

\section{Introduction}

The sliding hip screw (SHS) is a commonly used implant to treat proximal femoral fractures. It has been a well-established treatment option for stable pretrochanteric fractures more than 50 years $(1,2)$. The biomechanical principle of this method is a controlled impaction and stable contact of the femoral fragments during fracture healing due to the screw sliding in the hip plate (3). Common causes of failure of this fixation are as follows: the fracture pattern (unstable, mutlifragmentary), osteoporosis, poor quality of fracture reduction, location of the screw in the femoral head and non-union (4). One of the aspects that we can affect is

${ }^{1}$ Department of Orthopaedics, Hospital Pelhrimov, Pelhrimov, Czech Republic, ${ }^{2} \mathrm{Czech}$ Technical University in Prague, Faculty of Biomedical Engineering - Department of Health Care Disciplines and Population Protection, Kladno, Czech Republic, ${ }^{3}$ Czech Technical University in Prague, Faculty of Mechanical Engineering, Laboratory of Biomechanics, Prague, Czech Republic, and ${ }^{4}$ Department of Orthopaedics and Traumatology, Third Faculty Medicine of Charles University and University Hospital Kralovske Vinohrady, Prague, Czech Republic, ${ }^{5}$ College of Polytechnics Jihlava, Czech Republic.

Address for correspondence: M. Hrubina, MD, Department of Orthopaedics, Hospital Pelhrimov, Slovanskeho bratrstvi 710, CZ-393 01 Pelhrimov, Czech Republic.

Phone: +420.728 .312008$

Acknowledgements: This study was supported by Czech Ministry of Education, Youth and Sports project "Transdisciplinary research in Biomedical Engineering II", No. MSM 6840770012. Its contents are solely the responsibility of the authors and do not necessarily represent the official views of the Czech Ministry of Education, Youth and Sports. the SHS placement. The biomechanical analysis based on the finite element method (FEM) may be useful for the prediction of mechanical failures caused by the sliding screw placement $(5,6)$. In the Hospital Pelhrimov, we have been using SHS method since 1996, and we performed almost 600 SHS osteosyntheses till the end of 2013. Due to the increasing number of the used implants and some postoperative complications we have focused on the causes of failure (7). In the clinical analysis, we found five different patterns of sliding screw placement by means of the anteroposterior $\mathrm{X}$-rays with different incidence of specific complications. Then we performed biomechanical FEM analysis (8). In our previous study, we have tried to determine the optimum and risk position of the implant in 308 cases (9). The question is, if the used method (finite element model) is valid and can be used in other simulations. Therefore we decided to evaluate larger group of patients and to focus on specific implant-associated complications after treatment of stable pertrochanteric fractures by means of the sliding hip screw. As the hypothesis being tested in this study, we compared these clinical results with the numerical simulations using the finite element method (FEM) in order to investigate the relationship of the sliding screw failure patterns and the screw location. Due to the obtained results the finite element model validation was possible.

\section{Material and methods}

\section{Clinical study}

The monitored group consisted of 365 patients over 50 years old. In the framework of this group, 380 SHS osteosyntheses were 


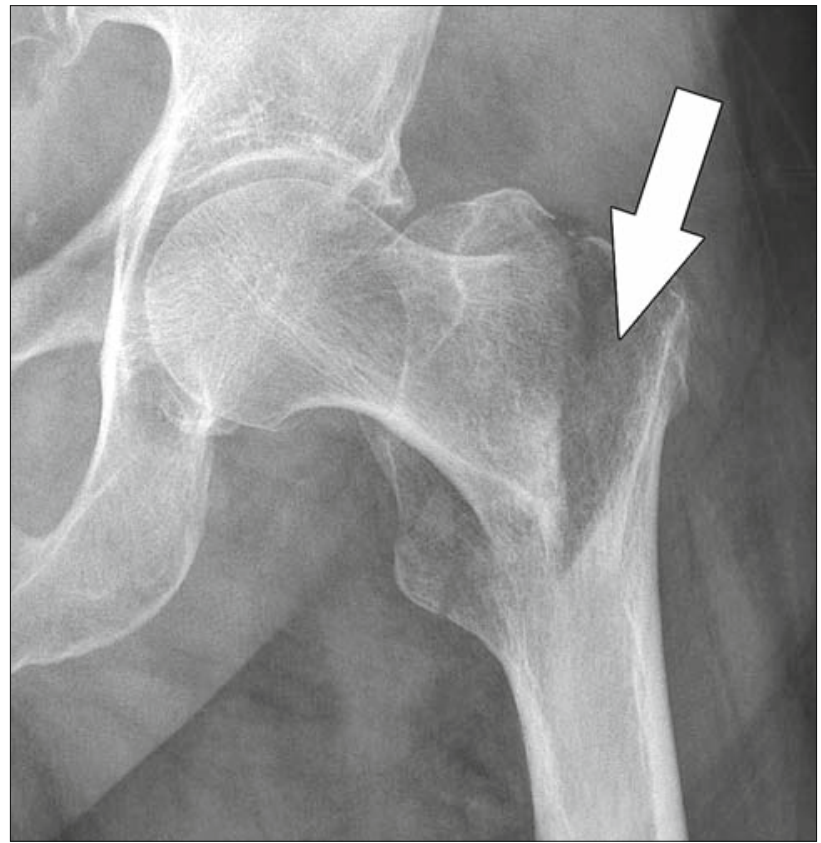

Fig. 1. X-ray of a patient (woman aged 78 years). The anteroposterior view of the left femur with a stable pertrochanteric fracture. The fracture line is indicated with the arrow.

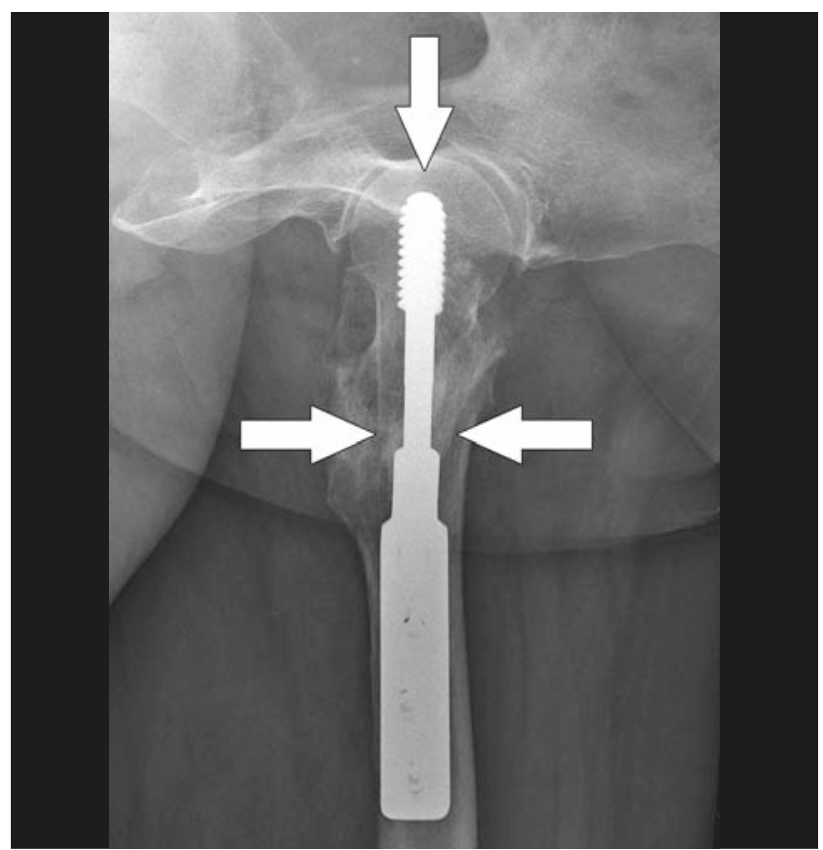

Fig. 2. X-ray of a patient (woman aged 78 years). The axial view, 7 days after the sliding screw osteosynthesis for stable pertrochanteric fracture of the left hip. The screw placement is centrally in the femoral neck and head - indicated with arrows.

performed (15 patients were operated on both sides). In all cases involved, we used $135^{\circ}, 1^{\prime \prime}$ collar (short barrel), 3-holes hip plate with sliding screw thread of $33 \mathrm{~mm}$ (Medin, a.s. Nove Mesto na Morave, Czech Republic) in the period 1997-2012. The followup period was one year. In this retrospective cohort study, the
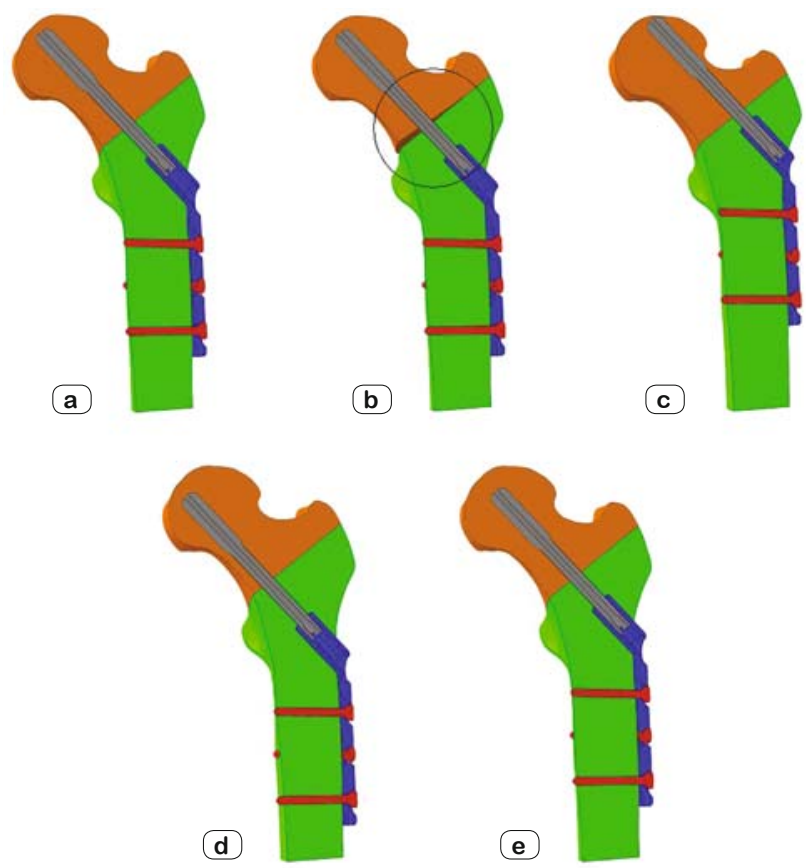

Fig. 3. Five model situations of the sliding screw placement in the femoral neck in anteroposterior view. a - Optimal placement in the middle third of the neck, which corresponds with Model I and Position 1, b - opened fracture line medially (indicated with the circle) corresponds with Model II and Position 2, c - location of the screw in the superior third of the neck associated with the highest risk of complications corresponds with Model III and Position 3, d - with screw location in the inferior third of the neck corresponds with Model IV and Position 4, e - with insufficient subchondral screw fixation corresponds with Model V and Position 5.

patients' records were reviewed retrospectively for demographic data, details of operation and follow-up results.

We conducted a standard diagnosis based on the assessment of anteroposterior X-ray view of the pelvis and injured hip. The group included only patients with stable pertrochanteric fracture: AO/OTA 31-A1.1, 31-A1.2 (Fig. 1). The surgery was performed in a standard way in spinal anesthesia. We plotted sliding screws in different locations of the anteroposterior view (which was recorded retrospectively), but centrally in the axial X-ray view in each case (Fig. 2). Patients stayed one or two days in the intensive care unit postoperatively, then further treatment proceeded in a standard department. The verticalisation and walking with crutches was conducted on the third to fourth day after the operation. The duration of hospitalization was 4-22 days (8 days on average). Walking with crutches with no weight bearing was recommended at least to the first inspection with the X-ray after six weeks since the operation. The full weight bearing was allowed in cases with a good clinical and radiological outcome after twelve weeks since the surgery. Further clinical and X-ray examination was performed in the 6th and 12th month postoperatively.

When evaluating radiographs, the blinded examiner (radiologist) observed the screw placement in the anteroposterior view, the change of the screw position superiorly (proximalisation) 


\section{2-310}

or protrusion from the femoral head (,cut-out“ phenomenon), the osteosynthetic material breaking or non-union (the persistent fracture line more than six months, the marginal bone resorption and the sclerotic bone of both fragments in the area of fracture).

We did not measure the tip-apex distance (10), the lenght of sliding and cortical screws, the fracture compression grade, the fracture healing time, the leg length and the degree of the osteoporosis.

The X-ray findings were divided into five subgroups according to the sliding screw position in the postoperative anteroposterior view (Fig. 3). In addition to the X-ray findings, we observed the re-operation rate.

The implant failure was defined as a situation with a specific complication of the osteosynthesis demanding reoperation. Subsequently, according to the five observed variants of the screw location in the femoral neck for our group of patients, the finite element model was developed.

\section{Finite element modelling}

First, standard parameters (based on our clinical observations) for the model were determined:

(a) Stable pertrochanteric fracture - the fracture line goes just above the lesser trochanter, ventrally in the area of linea intertrochanterica, where the reference points were selected in one third distance in between tuberculum trochantericum and tuberculum innominatum, dorsally going into the area of crista intertrochanterica,

(b) Proximal femur with collum-diaphysis angle (CCD-angle) $135^{\circ}$ of the femoral neck with $15^{\circ}$ of anteversion,

(c) The possibility of the line opening medially in the Adams arch by $4 \mathrm{~mm}$ (based on our clinical observation of fractures, where the opening was about $3-5 \mathrm{~mm}$ in 24 cases) (Fig. $3 b$ ).

The geometric model of the proximal femur was created from a series of CT-scans of one healthy individual - man aged 55 years. The images were taken at a resolution of $512 \times 512$ pixels, pixel size was $0.412 \mathrm{~mm}$ and the distance of each slice was $0.5 \mathrm{~mm}$. CT images were imported in DICOM format. The software Mimics 12 (Materialise, Belgium) was used in which the three-dimensional reconstruction of the femoral fragments was realized. The geometric model was created using the surface triangle net that was imported into the program ABAQUS 6.9 (Simulia, France), in the format *.inp. In this program the volume FEM (Finite Element Method) network was subsequently automatically generated from the surface structure. The sliding screw model was provided by Medin in format *.SAT, which was imported into the computational program too. Individual parts of the broken femur, the sliding screw and the cortical screws were created by the volume linear tetrahedron C3D4 elements. The FEM was used to evaluate the deformation and strain response of bone model to load. As a limit state, the failure occurs when fixation elements or failures of its attachment in the bone were exposed to such a load, that caused tensions exceeding the yield stress $\left(\sigma_{\mathrm{k}}\right)$ or the strength $\left(\mathbf{R}_{\mathrm{m}}\right)$ in any part of the modeled system "sliding screw - hip plate - cortical screws - bone". With regard to the complexity of the computations, FEM models were simplified by not including the thread profile included in any
Tab. 1. Material properties used for the sliding screw.

\begin{tabular}{lcccc}
\hline Material & $\begin{array}{c}\text { Elastic modulus } \\
\mathrm{E}(\mathrm{MPa})\end{array}$ & $\begin{array}{c}\text { Poisson's ratio } \\
\mu(-)\end{array}$ & $\begin{array}{c}\text { Strength } \\
\mathrm{Rm}(\mathrm{MPa})\end{array}$ & $\begin{array}{c}\text { Yield stress } \\
\sigma_{\mathrm{k}}(\mathrm{MPa})\end{array}$ \\
\hline Stainless Steel & 210000 & 0.3 & 860 & 690 \\
\hline
\end{tabular}

part of the model. The thread screws were replaced by smooth surfaces, the size of which corresponded with average diameter of the given thread.

The stainless steel used to produce sliding screw was modeled as a homogenous, isotropic and elastic-plastic material in all FEM analyses. The material properties are shown in Table 1. The bone tissue was in all analyses modeled as inhomogenous, isotropic and elastic-plastic material $(8,9)$. The material properties were determined for each element depending on the density of bone tissue $\rho\left(\mathrm{g} / \mathrm{cm}^{3}\right)$. This density was determined depending on the degree of gray colour in the CT scans and was calculated according to the ratio (1),

$$
\rho=1.54 \cdot \rho_{C T}+0.0784
$$

where $\rho_{C T}\left(\mathrm{~g} / \mathrm{cm}^{3}\right)$ is the density of the calibration sample. The modules of elasticity $\mathrm{E}(\mathrm{MPa})$ were for both types of bone tissue (compact - superscript " $k$ " and spongiosis - superscript "s") determined using the relations $(2-4)$. Poisson's ratio $(\mu)$ for both types of the bone tissue was 0.3 .

$$
\begin{aligned}
& E^{k}=2065 \rho^{3.09}, \mu^{k}=0.3 \\
& E^{s}=1904 \rho^{1.64}, \mu^{s}=0.3
\end{aligned}
$$

In the same way, the yield stress $\sigma_{\mathrm{k}}(\mathrm{MPa})$ was set as a function dependent on the value of bone tissue density according to:

$$
\begin{aligned}
& \sigma_{k}^{k}=57.75 \rho^{1.73} \text { for } \rho \geq 0.945 \\
& \sigma_{k}^{s}=76.5 \rho^{6.7} \text { for } \rho<0.945
\end{aligned}
$$

In numerical analyses, the bone tissue was also modeled as a material in which exceeding the load limit leads to degradation of its mechanical properties. This property can be understood as "damage" to bone tissue. These modeled properties are best illustrated in Figure 4, where a line graph shows the relationship between the stress and strain.

The individual values that unambiguously describe the behavior of the material model, when exceeding $\sigma_{\mathrm{k}}$ were also determined in relation to the density of bone tissue $\rho$ according to:

$$
\begin{array}{ll}
\sigma_{\min }=8.5 \rho^{3.68} & \varepsilon_{a b}=0.258 \rho-0.04 \\
E_{\rho}=-244 \rho^{2.2} & \varepsilon_{b c}=\frac{\sigma_{k}-\sigma_{\min }}{E_{\rho}}+\varepsilon_{a b}
\end{array}
$$

\section{Modeled positions}

In our own evaluation of the numerical model in relation to the clinical group of patients, we simulated these five situations ("position" means the placing of SHS in practice and model simulation): 


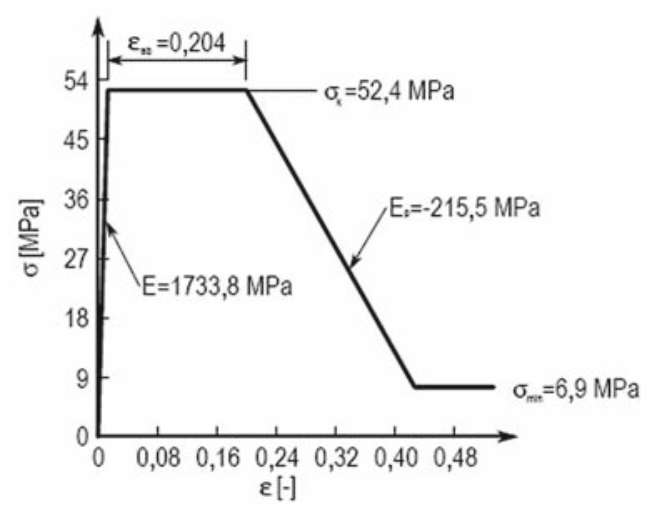

Fig. 4. Specification of the material properties. Illustration of the relationship between stress $\sigma(\mathrm{MPa})$ and strain $\varepsilon(-)$ of bone tissue with density $\rho=0.945\left(\mathrm{~g} / \mathrm{cm}^{3}\right)$.

Position 1 (Model I) - sliding screw placement in the middle third of the femoral neck with subchondral fixation (the end of the screw was placed between 5-10 $\mathrm{mm}$ from the femoral head edge - Fig. 3a)

Position 2 (Model II) - screw location in the middle third of the neck with subchondral fixation and opening the fracture line distally and medially to $4 \mathrm{~mm}$ (Fig. 3b).

Position 3 (Model III) - screw location in the superior third of the femoral neck with subchondral fixation (Fig. 3c).

Position 4 (Model IV) - screw placement in the inferior third of the femoral neck with subchondral fixation (Fig. 3d).

Position 5 (Model V) - sliding screw location in the middle third of the femoral neck with the fixation in the femoral head more than $10 \mathrm{~mm}$ from the edge (Fig. 3e).

\section{Boundary conditions and loading}

The purpose of our analyses was to determine the response of bone tissue, when loading the proximal femur, in relation to the position of the implanted sliding screw. We simulated the condition, when osteosynthesis was loaded immediately after the surgery with the maximum low-cycle high stress loading. Therefore, it was possible to opt for a simplified method of making the proximal femur fixed (Fig. 5). The loading was realized by applying individual external forces coming from the musculus iliopsoas and musculi glutei and the resulting reaction in the acetabulum. To simulatate external forces to the FEM analyses, we used a DISTRIBUTED COUPLING, by which single forces acting in a control reference node were equally distributed to the bone tissue and tendon attachment points and contact of the femoral head with the acetabulum (Fig. 5a). During the analyses, the model was loaded using separated forces: $\mathrm{F}_{\text {glut }}=642.3 \mathrm{~N}, \mathrm{~F}_{\text {iliop }}=376.4 \mathrm{~N} \mathrm{a} \mathrm{F}_{\text {reac }}=1000 \mathrm{~N}$, which act on the hip joint, while walking without support, for an individual weighing $80 \mathrm{~kg}$ (6). The space between fragments of the femur was modeled using contact of the HARD type, with a coefficient of friction $f=0.3$. This coupling simulated a real situation, when mutual penetration of individual parts was not possible, but their mutual seclusion was tolerable. The same method was also used for modeling contact couplings between the sliding screw and bone $(f=0.3)$, between the sliding screw and the hip plate $(f=0.15)$, and between the plate and the bone $(f=0.3)$. All the listed contact couples are highlighted in Figure 5b. Coupling of bone with cortical screws, coupling of cortical screws with the hip plate, and the coupling of the sliding screw with bone were modeled, with regard to speed and stability of the computations, modeled using TIE contact (Fig. 5c). In ABAQUS, this specific type of contact represents a firm coupling of two parts, where the nodes of both contact parts have a firm mutual coupling. This coupling transfers the same value for the size of the shift from the superior contact plate to the subordinate contact plate (8).

We compared the clinical results with the FEM simulations in each position.

Software Statistica (version 12) was used for statistical analysis of the clinical study.

The clinical interpretation of our results with the ones of FEM analyses for proximal femur were done according to the suggestions of Vicecontii et al (11).

Tab. 2. The number of sliding screw osteosyntheses divided according to the position of the screw into 5 subgroups which were the subject of FE model analyses.

\begin{tabular}{lcrlrl}
\hline & $\begin{array}{c}\text { Number of } \\
\text { osteosyntheses }\end{array}$ & Complications & Reoperations \\
\hline Position 1 (model I) & 182 & 15 & $(8.2 \%)$ & 5 & $(2.7 \%)$ \\
Position 2 (model II) & 24 & 1 & $(4.2 \%)$ & 0 & $(0 \%)$ \\
Position 3 (model III) & 5 & 5 & $(100 \%)$ & 5 & $(100 \%)$ \\
Position 4 (model IV) & 153 & 13 & $(8.5 \%)$ & 4 & $(2.6 \%)$ \\
Position 5 (model V) & 16 & 4 & $(25 \%)$ & 2 & $(12.5 \%)$ \\
\hline Total & 380 & 38 & $(10 \%)$ & 16 & $(4.2 \%)$ \\
\hline
\end{tabular}

Tab. 3. The statistical analysis of the studied group of patients. Incidence of complications and reoperations.

\begin{tabular}{|c|c|c|c|c|}
\hline \multicolumn{5}{|c|}{ Complications } \\
\hline & Position 2 & Position 3 & Position 4 & Position 5 \\
\hline Position 1 & p 0.4192 (F test) & $\mathrm{p}<0.0001$ (F test) & $\mathrm{p}=0.9331$ (chi sq. test) & $\mathrm{p}=0.0525(\mathrm{~F}$ test $)$ \\
\hline Position 2 & & $\mathrm{p}=0.0001(\mathrm{~F}$ test $)$ & $\mathrm{p}=0.4059(\mathrm{~F}$ test $)$ & $\mathrm{p}=0.0730(\mathrm{~F}$ test $)$ \\
\hline Position 3 & & & $\mathrm{p}<0.0001$ (F test) & $\mathrm{p}=0.0062(\mathrm{~F}$ test $)$ \\
\hline Position 4 & & & & $\mathrm{p}=0.0599(\mathrm{~F}$ test $)$ \\
\hline \multicolumn{5}{|c|}{ Reoperations } \\
\hline & Position 2 & Position 3 & Position 4 & Position 5 \\
\hline Position 1 & $\mathrm{p}=0.5348(\mathrm{~F}$ test $)$ & $\mathrm{p}<0.0001$ (F test) & $\mathrm{p}=0.6067(\mathrm{~F}$ test $)$ & $\mathrm{p}=0.1014(\mathrm{~F}$ test $)$ \\
\hline Position 2 & & $\mathrm{p}<0.0001$ (F test) & $\mathrm{p}=0.5553(\mathrm{~F}$ test $)$ & $\mathrm{p}=0.1538(\mathrm{~F}$ test $)$ \\
\hline Position 3 & & & $\mathrm{p}<0.0001$ (F test) & $\mathrm{p}=0.0010(\mathrm{~F}$ test $)$ \\
\hline Position 4 & & & & $\mathrm{p}=0.1009(\mathrm{~F}$ test $)$ \\
\hline
\end{tabular}



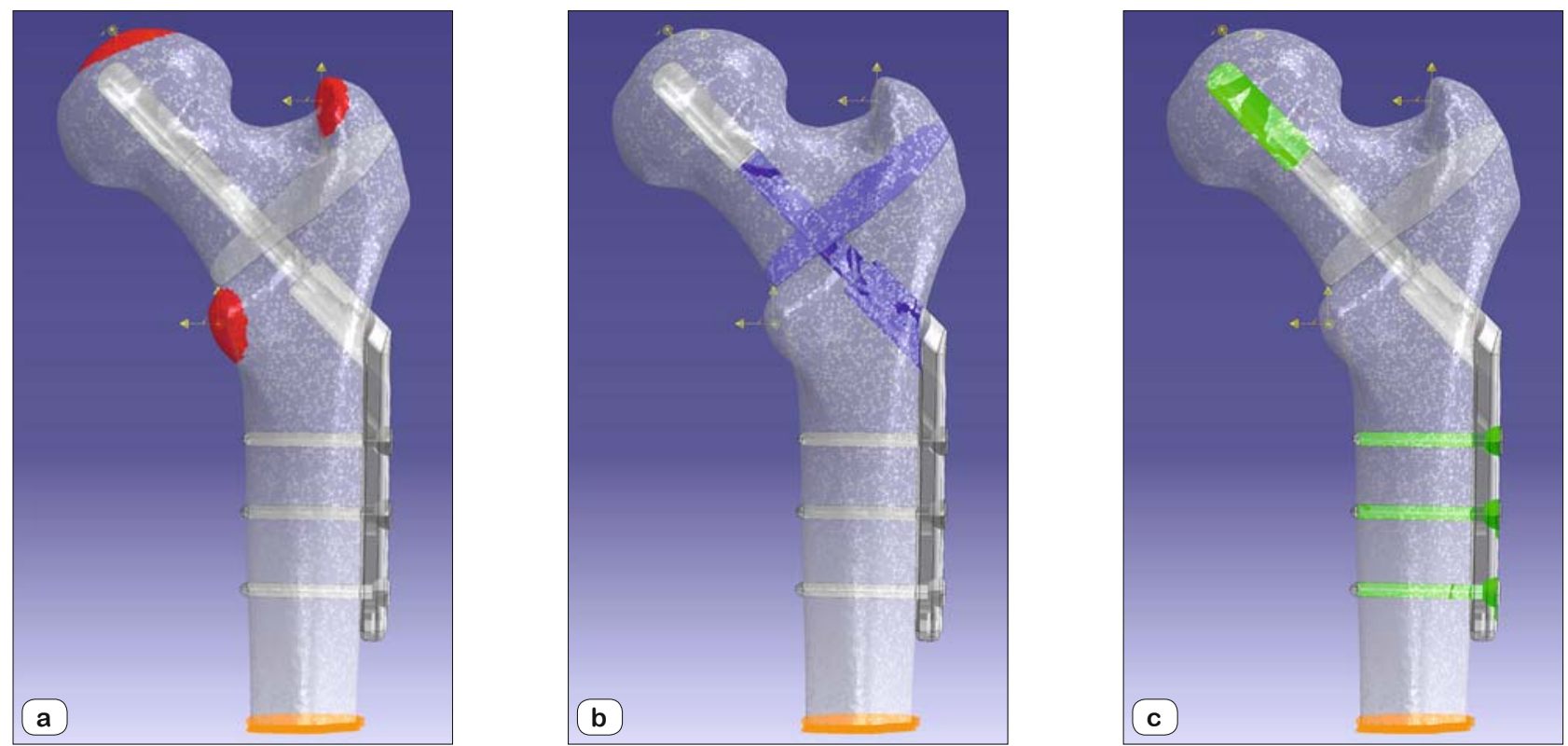

Fig. 5. Boundary conditions and loading. a - illustration of used Distributed Coupling for distribution of the forces affecting the surface of the ligament, $b$ - illustration of contact couplings in the numerical FE model, $c$-illustration of TIE coupling usage in the numerical FE model.

This study was approved by the Ethical Commitee of the Hospital Pelhrimov, in which it was performed, and all subjects gave their informed consents.

\section{Results}

\section{Clinical study}

The age of patients in studied cohort ranged from 50-102 years with an average of 83.6 years. The number of women was 274 (75 $\%$ ) and men 91 (25\%), the women predominating over men in ratio 3:1. Lateral involvement has almost been balanced (188 times right side, 192 times left side). SHS was performed bilaterally for 15 patients, 14 months after the previous osteosynthesis on average.

From the total of 380 performed and analysed osteosyntheses, we recorded 38 specific complications ( $10 \%)$. The total of 16 patients with 16 sliding screws ( $4.2 \%$ ) were re-operated due the specific complications with the implant failure. The incidence of complications in each of five observed screw positions is shown in Table 2.

In position 1, there were 15 specific complications (1: nonunion with sliding screw breakage, 2 : cortical screws breakage, $2 \mathrm{x}$ : „cut-out", 10: screw position change). We re-operated 5 patients

Tab. 4. The resultant values of the reduced stress $\sigma_{\text {нмн }}(\mathrm{MPa})$ in particular parts of $\mathrm{FE}$ model of the proximal femur and sliding screw.

\begin{tabular}{lccccc}
\hline & $\begin{array}{c}\text { Proximal } \\
\text { bone } \\
\text { fragment } \\
\sigma_{\mathrm{HMH}}(\mathrm{MPa})\end{array}$ & $\begin{array}{c}\text { Distal } \\
\text { bone } \\
\text { fragment }\end{array}$ & Hip plate & $\begin{array}{c}\text { Sliding } \\
\text { screw }\end{array}$ & $\begin{array}{c}\text { Cortical } \\
\text { screws }\end{array}$ \\
\hline Model I & 170.6 & 192.9 & 436.5 & 435.3 & 693.1 \\
Model II & 83.1 & 168.5 & 703.8 & 716.6 & 695.5 \\
Model III & 106.7 & 192.9 & 729.8 & 713.8 & 706.6 \\
Model IV & 123.9 & 192.9 & 717.3 & 698.1 & 698.2 \\
Model V & 165 & 164.2 & 699.5 & 691.6 & 698.4 \\
\hline
\end{tabular}

with osteosynthetic material breakage and ,cut-out“. 10 patients with changed screw position during the fracture healing (proximalisation from the middle third to the superior third of the neck) were without need for re-operation.

In position 2, there was only one patient with a screw proximalisation without a need for re-operation.

In position 3, there were only 5 osteosyntheses, but the ,cutout" with the need for re-operation was found in all of them.

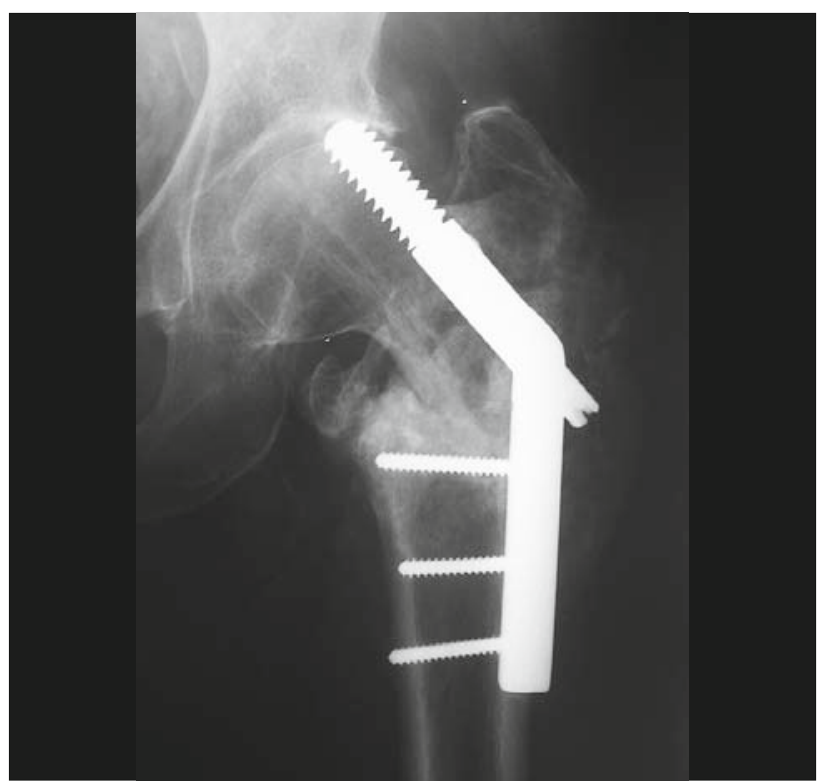

Fig. 6. X-ray of a patient (woman aged 69 years). The anteroposterior view of the left femur with "cut-out" phenomenon of the sliding screw 6 months after the surgery. The failed screw was placed in the superior third of the femoral neck. 
In position 4, there were 13 specific complications (1: nonunion with sliding screw breakage, 3 : „cut-out“, 9: screw position change). We re-operated 4 patients with metal breakage and „cut-out".

In position 5, there were 4 specific complications (2: ,cutout", 2: screw position change) with the need for re-operation of „cut-out" in 2 cases.

It is evident from the Table 2 that the most frequent positions in the framework of our group of osteosyntheses were positions 1 and 4 . The most serious problem was the sliding screw placement in the position 3 (Fig. 6), which led to complications requiring reoperation in $100 \%$ cases, and then position 5 , where we had to re-operate $12.5 \%$ cases. The Chi-squared test was used for the evaluation of difference between incidences of complications when the screw was in position 1 and 4 . For all other differencies the Fishers exact test was used because of a small sample size (position 2, 3 and 5). It is evident from Table 3.

The ,cut-out" phenomenon was found in 12 cases (3.2\%) of the whole group of patients.

\section{Finite element analysis}

The evaluation of numerical FEM simulations suggests the following conclusions. All performed numerical analyses were modeled as a contact, nonlinear and static tasks in which a response of the entire system to applied loading exposures was analyzed. The performed computational FEM analysis regarded local mechanical properties of the bone tissue in great detail. The corresponding results obtained are summarized in Table 4 and in Figures 7 and 8.

From the results of FEM simulations listed in Table 4, it is clear, that the stress in the whole model of the femur and sliding screw with hip plate was significant during the tested loading. The bone tissue of the femur has in all models the highest loading exposition mainly in the area of lower cortical screw, which fixes the hip plate. In this part of the femur the maximum values of reduced stress $\sigma_{\text {нмн }}$ range from 164.2 MPa (Model V) to 192.9 MPa (Model I, III, IV). In this part of the model, we also found clear damages of bone tissue at the level of the fracture and of the gap through which the sliding screw was placed. The bone tissue of the proximal femoral fragment undergoes the highest loading in the area of the lower edge of the femoral neck at the level of the fracture plane in all models except Model II. In this area, the proximal fragment leans against the distal fragment. The maximum values of reduced stress $\sigma_{\mathrm{HMH}}$ range from 83.1 (Model II) to 170.6 (Model I). In contrast, Model II shows the maximum loading of the bone tissue at the hole in which the sliding screw is located (close to the fracture plane). In fact, all modeled situations showed clear damages of the bone tissue in the fracture plane associated with the opening through which the sliding screw passes (Fig. 8). In terms of evaluation of bone tissue response to external loading according to various sliding screw locations, the type of stress distribu-
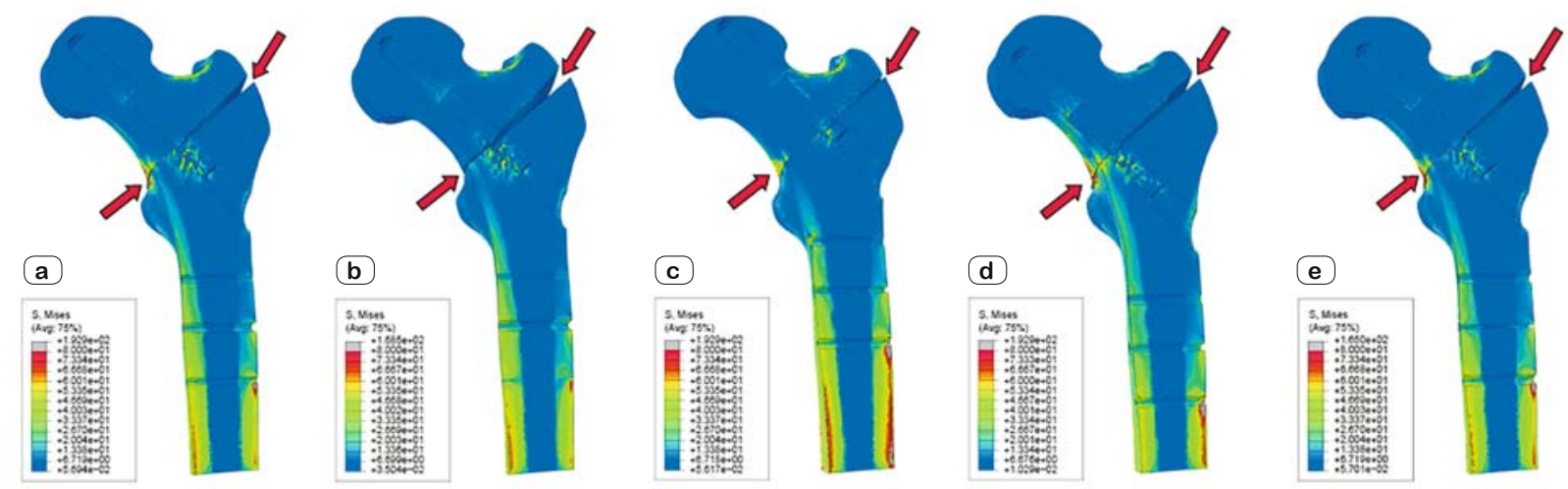

Fig. 7. The reduced stress distribution (von Mises stress) $\sigma_{\text {нмн }}$ (MPa) in the distal fragment of the femur in 5 model situations. The fracture lines are indicated with the arrows. The screws and the plates were removed. In all figures there was a compression of the fracture line medially and in Figures $7 \mathrm{a}, 7 \mathrm{~b}, 7 \mathrm{~d}$ and $7 \mathrm{e}$, there was a mild distraction in the area of great trochanter. The maximal value of the stress is in the area of distal cortical crew in all positions.
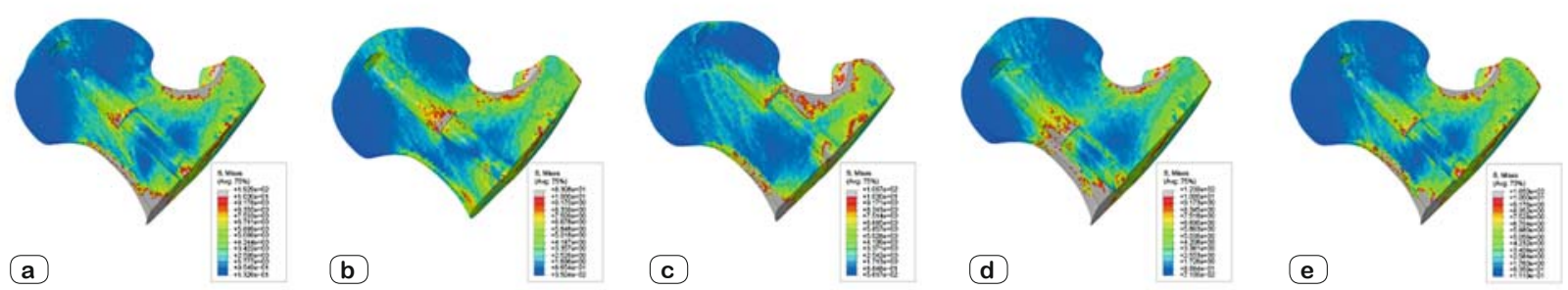

Fig. 8. The reduced stress distribution (von Mises stress) $\sigma$ HMH (MPa) in the cut of the proximal fragment (femoral head, neck and part of the great trochanter) in 5 model situations. The screw was remowed from the picture, the optimal position is Figure 8a, where is an equal bone load in the head and neck. The highest risk of complications is associated with Figure 7c, with location of the screw in the superior third of the neck. The most loaded part of the neck is the lower edge in the area of the fracture line (except Fig. 8b). 
tion was found to be important. For successful osteosynthesis, it is important to achieve a uniform distribution of stress across the entire femoral head. The optimum condition is shown in Figure $8 \mathrm{a}$, where the femoral neck is loaded equally in both (superior and inferior) halves. The transfer of stress from the sliding screw to the femoral head occurs mainly at the level of the border between the head and neck. In Model III and Model IV, the unequal transfer of loading from the inferior to the superior part of the femoral neck is visible in relation to the position of the femoral screw (Figs 8c, 8d). The similar situation can be also seen in Model II, where the wedge-shaped cut at the fracture site is located. As it is clear from Figure $8 b$, the stress (loading) is shifted to the superior part of the femoral neck, while the inferior edge transfers only a minimum loading. At the same time, the stress increased, in the area of femoral head is visible around the sliding screw thread. An objective of the numerical FEM analyses was also to evaluate the sliding screw stress. The resulting values of the reduced stress $\sigma_{\text {нмн }}$ are listed in Table 4. The results clearly show that the loading of the sliding screw (for the anticipated loading forces) was relatively high, and exceeded yield stress value $\sigma_{\mathrm{k}}$. The values of the stresses on the hip plate and cortical screws were close to the yield stress; however, their magnitude is affected by the TIE coupling used for joining the cortical screws with the hip plate. The maximum values $\sigma_{\text {нмн }}$ for the plate ranged from 436.5 MPa (Model I) to 729.8 $\mathrm{MPa}$ (Model III). For the lower cortical screw, the range was between 693.1 MPa (Model I) to 706.6 MPa (Model III). The sliding screw presents a different situation. The stress is not affected by any couplings; however, the $\sigma_{\mathrm{HMH}}$ was still higher than $\sigma_{\mathrm{k}}$. The value of maximum $\sigma_{\mathrm{HMH}}$ was determined to be in a range between 435.3 MPa (Model I) to 716.6 MPa (Model II). In particular, the screw placement in the superior third of the femoral neck (Model III with $\sigma_{\mathrm{HмH}}=729.8 \mathrm{MPa}$ for the hip plate and $\sigma_{\mathrm{HмH}}=713.8 \mathrm{MPa}$ for the sliding screw) increases the corresponding strain (even by more than $63 \%$ in comparison to Model I with $\sigma_{\mathrm{HMH}}=436.6 \mathrm{MPa}$ for the hip plate and $\sigma_{\mathrm{HмH}}=435.3 \mathrm{MPa}$ for the sliding screw). The comparison of clinical and FEM simulation results

We found the maximum incidence of specific complications for the sliding screw failures in positions 3. The optimal screw placement is in positions 1 and 2. Position 4 is acceptable due to the clinical results. The FEM simulations prefer as optimal the sliding screw placement (due to the stress distribution) in Model I and II. The highest risk of the osteosynthesis failure is in Model III. An acceptable position is in Model IV.

\section{The Finite element validation}

Due to the recorded clinical and biomechanical analysis, we found our FEM model valid especially in position 3, Model III.

\section{Discussion}

The sliding hip screw has been a well-established treatment method for stable proximal femoral fractures $(2,3,12)$. However, the reported revision rate was in range of $4 \%$ to $12 \%(13,14)$, and the complications of failed fixation led to the femoral head cut-out rates of $1.7 \%$ to $6.8 \%(7,9,15,16)$. Our results are within the above mentioned ranges. We found a reoperation rate of $4.2 \%$ and the ,cut-out" phenomenon of $3.2 \%$ in total.

The position of the implant in the femoral head can also significantly influence the outcome of the fixation (17). Tip-apex distance (TAD) is well known and frequently analyzed method for the prediction of the sliding screw failure especially by the „cut-out" $(10,18)$. Parker found, that cutting out occurred more frequently when screws were placed superiorly or posteriorly (19). Davis et al preferred the central position in both views (20). Mainds, Newman and Thomas considered the central or inferior position in the anteroposterior view to be better due to cutting out resistance $(21,22)$. Hsueh et al. have found the highest incidence of the sliding screw failure in the superior third of the femoral head in the clinical study (15).

Yian et al used biomechanical analyses with the cadavers for the study of plate fixation. They have found, that three cortical screws are enough for the plate fixation (23). We prefer 3-holes side plates. Luo et al performed a similar study to ours. They analyzed sliding screw fixation of the unstable pertrochanteric fractures with the helical blade applying synthetic proximal femoral bones. They used vertical cyclic loading forces of $500 \mathrm{~N}$ and 900 $\mathrm{N}$ and founded the optimal placement of the implant centrally in the femoral head and neck (the screw placement in the inferior third of the neck was acceptable (17)). We found the same results in positions 1, 4 and Models I and IV. The finite element method has reproducible results in modeling (24). Yuan et al compared the internal fixation of osteoporotic intertrochateric fractures with proximal femoral nail and dynamic hip screw against the finite element analysis (25). They used CT scans in three cases with different fracture patterns with the slice thickness of $0.625 \mathrm{~mm}$. The Poisson's ratio was 0.3 . The maximum value of the reduced stress of the sliding screw was $1604.3 \mathrm{MPa}$, but the authors analyzed different types of fractures and did not consider the role of the soft tissues (muscles around the hip joint). The method of comparing the selected clinical information and the model situation in our study confirms that clinical risk situations present indeed a significant occurence of specific complications (26).

From the view of age and sex distribution is our group of patients similar to ones presented by other authors (27). A clear connection with the subsequent complications that were re-operated was found when the sliding screw was placed in the superior third of the neck (position 3), which led to ,cut-out“ of the femoral head in five patients. Clinical monitoring regularly identified the best results in situations, where the femoral reduction was done exactly (in the case of opening the fracture line medially too, which allows controlled fracture compression), with placement of the screw in the middle of the neck or in the inferior third with subchondral fixation (position 1, 2, 4). A re-operation rate from 0 $\%$ to $2.7 \%$ in this subgroup of patients is comparable with other studies $(12,28)$. A screw placement in the center of femoral head (not subchondral) presents $12.5 \%$ risk of re-operation. These findings correspond to the results of numerical FEM simulations. Our study is limited for some reasons. First, an FEM analysis always assumes certain simplifications, e.g. the bone quality (osteoporosis) was not assessed in this analysis (29). Second, connections were 
realized by TIE binding, which does allow to distract the contact surfaces. Another important factor that significantly affects the interpretation of the obtained results, is the character of the whole investigation. Simulations were modeled as a static task, which is able to describe only a single load moment (high stress) and the system response to this load. We analyzed the situation, which may occur early after the surgery, with the full weight bearing of the implant. In a real situation, the sliding hip screw and the bone are loaded by repeated pulsative forces which also have not a constant value (30). In our opinion, the presented results of the numerical FEM simulations can deliver a number of conclusions and recommendations.

All presented results show, from a biomechanical point of view, that the optimum sliding screw position is very important. The position of screw directly affects not only the magnitude and the type of loading on the bone tissue of the femur, but also the stress on the screw itself. Therefore, it must be emphasized that unless the sliding screw is in an optimal position, loading may exceed the allowed values of stress and increase the risk of an osteosynthesis failure. The results of FEM analyses presented in Table 4 show that the stress on the sliding screw exceeded the yield stress $\sigma_{k}$, at the end of the screw, in the area of contact with the plate, revealed parasitic stress $\sigma_{k}$ caused by the contact of the screw with the plate over a very small area (which is the type of imprecision associated with the FEM). However, exceeding the values of the yield stress in the screw was not affected by the coupling method used or the simplification. The potential risk of the sliding hip screw osteosynthesis failure is also significantly increased by the periodic character of femur loading (which was not considered in our analyses). The risk of failure can be decreased only through optimal screw placement, a suitable rest period after surgery, and prompt initiation of the fracture healing. The FEM analyses and results listed in Table 4 also illustrate, that both fragments of the femur in the area around the hole in the hip plate, in the plane of the fracture, were susceptible to a permanent degradation of the bone tissue. This condition was caused by significant bending of the sliding screw and the consequential pressure on bone tissue. Loading of the bone tissue is, therefore, also closely connected to the position of the screw in the bone. In order to achieve a long sliding hip screw lifespan, it is necessary to distribute the stress (loading) equally in the surrounding bone tissue. Any deviation (however small) from the optimal position has a significant influence on the stress of the whole system and the risk of the osteosynthesis failure increases dramatically. Despite the above-mentioned reservations, simplifications and generalizations, it is possible to accept the presented results as representative. Our objectives were not to conduct a detailed evaluation of the individual components of the model but to compare, under equal conditions, the response of bone tissue to different sliding screw positions commonly. When we compare the clinical study and biomechanical analyses of the risk position 3 (Model III), the results correspond. The screw placement in the superior third of the femoral neck significantly increases the risk of the osteosynthesis failure and increases strain of the plate and screw by more than $63 \%$.

\section{Learning points}

Biomechanical analysis, trauma, hip, proximal femoral fractures, sliding hip screw, specific complications.

\section{Conclusion}

The performed FEM numerical simulations show that the optimal sliding screw position is in the middle of the femoral neck with subchondral fixation. A possible opening of the fracture line medially in compliance with the above rules does not increase the risk of specific complications. On the other hand, the screw placement in the superior third of the femoral neck is connected with significant risk. All obtained results from FEM simulations were confirmed in a clinical study. The sliding screw placement in the superior third of the neck always leads to osteosynthesis failure and re-operation. The complication rate within the group of patients was $10 \%$, with the re-operation rate of $4.2 \%$. Our FEM analyses results correspond to clinical observations. Our finite element method model provides valid results and can be useful for biomechanical studies of another implant (proximal femoral nail) in the future.

\section{References}

1. Schumpelick W, Jantzen PM. A new principle in the operative treatment of trochanteric fractures of the femur. J Bone Jt Surg 1955; 37A (4): 693-698.

2. Bonnaire F, Lein T, Bula P. Trochanteric femoral fractures: Anatomy, biomechanics and choice of implant. Unfallchirurg 2011; 114 (6): 491-500.

3. Dousa P, Cech O, Weissinger M, Dzupa V. Trochanteric femoral fractures. Acta Chir Orthop Traum Czech 2013; 80 (1): 15-26.

4. Arastu MH, Phillips L, Duffy P. An unusual failure of a sliding hip screw in the immediate post-operative period. Injury Extra 2013; 44 (2): $23-27$.

5. Haynes RC, Poll RG, Miles AW, Weston RB. An experimental study of the failure modes of the Gama Locking Nail and AO Dynamic Hip Screw under static loading: a cadaveric study. Med Eng Phys 1997; 19 (5): 446-453.

6. Keyak J, Falkinstein Y. Comparison of in situ and in vitro CT scanbased finite element model predictions of proximal femoral fracture load. Med Eng Phys 2003; 25 (9): 781-787.

7. Hrubina M, Skotak M, Behounek J. Complications of dynamic hip screw treatment for proximal femoral fractures. Acta Chir Orthop Traum Czech 2010; 77 (5): 395-401.

8. Horak Z, Hrubina M, Dzupa V. Biomechanical analyses of proximal femur osteosynthesis by DHS system. Bull Appl Mech 2011; 7 (27): 60-65.

9. Hrubina M, Horak Z, Bartoska R, Navratil L,Rosina J. Computational modeling in the prediction of Dynamic Hip Screw Failure in proximal femoral fractures. J Appl Biomed 2013; 11 (3): 143-151.

10. Baumgaertner MR, Curtin SL, Lindskog DM, Keggi JM. The value of the tip-apex distance in predicting failure of fixation of peritrochanteric fractures of the hip. J Bone Jt Surg 1995; 77A (7): 1058-1064. 


\section{2-310}

11. Viceconti M, Olsen S, Nolte LP, Burton K. Extracting clinically relevant data from finite element situation. Clin Biomech 2005; 20 (9): 451-454.

12. Barton TM, Gleeson R, Topliss C, Greenwood R, Harries WJ, T. Chesser TSJ. A comparison of the long gama nail with the sliding hip screw for the treatment of AO/OTA 31-A2 fractures of the proximal part of the femur. J Bone Jt Surg 2010; 92A (4): 792-798.

13. Palm H, Jacobsen S, Sonne-Holm S, Gebuhr P. Integrity of the lateral femoral wall in intertrochanteric hip fractures: an important predictor of a reoperation. J Bone Jt Surg 2007; 89A (3): 470-475.

14. Peyser A, Weil YA, Brocke I, Sela Y, Mosheiff R, Mattan Y, Manor $\mathbf{O}$, Liebergall M. A prospective, randomised study comparing the percutaneous compression plate and the compression hip screw for the treatment of intertrochanteric fractures of the femur. J Bone Jt Surg 2007; 89B (9): 1210-1217.

15. Hsueh KK, Fang CK, Chen CM, Su YP, Wu HF, Chiu FY. Risk factors in cutout of sliding hip screw in intertrochanteric fractures: an evaluation of 937 patients. Int Orthop 2010; 34 (8): 1273-1276.

16. Chirodian N, Arch B, Parker MJ. Sliding hip screw fixation of trochanteric hip fractures: outcome of 1024 procedures. Injury 2005; 36 (6): 793-800.

17. Luo Q, Yuen G, Lau TW, Yeung K, Leung F. A biomechanical study comparing helical blade with screw design for sliding hip fixations of unstable intertrochanteric fractures. Sci World J 2013; Article ID 351936.

18. De Bruijn K, Den Hartog D, Tuinebreijer W, Roukema G. Reliability of predictors for screw cutout in intetrochanteric hip fracture. J Bone Jt Surg 2012; 94A (14): 1266-1272.

19. Parker MJ. Cutting - out of the dynamic hip screw related to its position. J Bone Jt Surg 1992; 74B (4): 625.

20. Davis TRC, Sher JL, Horsman A, Simpson M, Porter BB, Checketts RG:.Intertrochanteric femoral fractures. Mechanical failure after internal fixation. J Bone Jt Surg 1990; 72B (1): 26-31.
21. Mainds CC, Newman RJ. Implant failures in a patients with proximal fractures of the femur treated with a sliding screw device. Injury 1989; 20 (2): 98-100.

22. Thomas AP. Dynamic hip screws that fail. Injury 1991; 22 (1): 45-46.

23. Yian EH, Banerji I, Mathews LS. Optimal side plate fixation for unstable intertrochanteric hip fractures. J Orthop Trauma 1997; 4 (11): 254-259.

24. Baca V, Horak Z, Mikulenka P, Dzupa V. Comparison of an inhomogeneous orthotropic and isotropic material models used for FE analyses. Med Eng Phys 2008; 30 (7): 924-930.

25. Yuan GX, Shen YH, Chen B, Zhang WB. Biomechanical comparison of internal fixations in osteoporotic intertrochanteric fracture. Saudi Med J 2012; 33 (7): 732-739.

26. Rohlmann A, Mößner U, Bergmann G, Kölbel R. Finite-element analysis and experimental investigation of stresses in a femur. J Biomed Eng 1982; 4 (3): 241-246.

27. Oestern HJ, Gänsslen A. The use of blade plate and dynamic screw plate osteosynthesis. Orthopade 2010; 39 (2): 160-170.

28. Knobe M, Munker R, Schmidt-Rohlfing B, Sellei RM, Schubert H, Erli HJ. Surgical outcome in pertrochanteric femur fracture: the impact of osteoporosis. Comparison between DHS and percutaneous compression plate. Z Orthop Unfall 2008; 146 (1): 44-51.

29. Ito M, Nakata T, Nishida A, Uetani M. Age-related changes in bone density, geometry and biomechanical properties of the proximal femur: CT-based 3D hip structure analysis in normal postmenopausal women. Bone 2011; 48 (3): 627-630.

30. Bergmann G, Deuretzbacher G, Heller M, Graichen F, Rohlmann A, Strauss J, Duda GN. Hip contact forces and gait patterns from routine activities. J Biomech 2001; 34 (7): 859-871.

Received May 7, 2014. Accepted May 22, 2014. 